\title{
Autosomal recessive sudden unexpected death in children probably caused by a cardiomyopathy associated with myopathy ${ }^{1}$
}

\author{
K. FRIED, S. BEER, E. VURE, M. ALGOM, AND Y. SHAPIRA \\ From the Departments of Genetics, Pediatrics, and Cardiology, Asaf Harofe Hospital, Tel-Aviv \\ University Medical School, Zerifin; and Department of Pediatrics, Hadassah University Hospital, \\ Mount Scopus, Jerusalem, Israel
}

\begin{abstract}
SUMMARY The propositus, who died suddenly at the age of 22 months, was investigated because of an unusual myopathy. Family history revealed two sisters and four cousins who had also died suddenly and unexpectedly. The finding of asymmetric septal hypertrophy by echocardiography in the propositus suggested that the cause of the sudden death in the relatives was an undetected cardiomyopathy accompanying a mild and often subclinical myopathy. The affected children were in two sibships and both sets of parents were first cousins. The mother of one sibship was the sister of the father of the other. It is suggested that a gene causes a mild autosomal recessive myopathy with cardiomyopathy that is often undiagnosed and usually ends in sudden unexpected death in the second year of life. The same gene may manifest on echocardiogram in some heterozygotes as asymmetric septal hypertrophy.
\end{abstract}

Sudden unexpected death in the second year of life is rare. In the Newcastle survey of deaths in early childhood 1974 to 1976 with special reference to sudden unexpected deaths, only one child died in this manner in the second year of life (Downham, 1977). The purpose of this report is to draw attention to a possible genetic cause for such an occurrence, probably the result of an often undiagnosed cardiomyopathy associated with a mild myopathy.

\section{Case report}

The propositus (Fig. 1) was born on 19.7.76 after 42 weeks of pregnancy. The delivery was spontaneous after premature rupture of the membranes. Birthweight was $3300 \mathrm{~g}$, placenta weight $500 \mathrm{~g}$. The Apgar score at one minute was 5 , and after 3 minutes of treatment with oxygen rose to 10 . His head circumference was $35 \cdot 5 \mathrm{~cm}$. The child was first brought to our attention when the parents noticed at the age of 6 months that he made few spontaneous movements and no attempt to sit up. Physical examination at the age of 7 months showed slight muscle weakness. The child did not sit or turn over, but did hold things in his hands. Electroencephalogram was normal.

${ }^{1}$ This research was supported in part by a grant from the Muscular Dystrophy Association of America.

Received for publication 8 January 1979
Detailed examination at the age of 8 months showed: he did not turn over but raised his head supported by arms with elbows almost straight; when pulled to

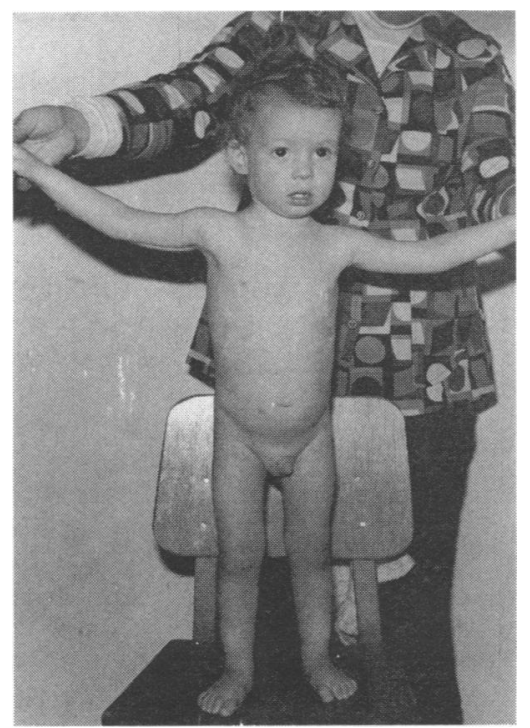

Fig. 1 The propositus at $1 \frac{1}{2}$ years old. Note minimal wasting of muscle, that could be undetected on casual examination, and absence of contractures. 
sitting position there was slight head lag; there was poor control of back, and when seated he fell over; he tried without success to use his arms to keep balance; when held in the standing position he bore weight on toes; there was moderately reduced muscle tone and muscle mass, and weakness in raising his arms. Tendon reflexes were normal to slightly reduced. Examination at 11 months showed: he turned over but did not crawl; there was marked weakness of the sternocleidomastoid muscles and generalised muscle weakness of both proximal and distal distribution; there were slightly reduced tendon reflexes, no pathological reflexes, no sensory disturbances, no fasciculations, and no contractures. At the age of one year the child was crawling and saying single words. At the age of 15 months he was able to sit with bent back. At 18 months he sat up alone, and walked with slight support holding on to furniture. At 20 months he started walking unaided and standing up alone. On auscultation, a 2/6 systolic murmur was heard at the lower parasternal border. The electrocardiogram was normal. Echocardiography showed a marked increase in the thickness of the septum. The thickness was $11 \mathrm{~mm}$, that is, the upper limit of normal adult size. There was also slight ventricular hypertrophy. The ratio of interventricular septum to posterior left ventricular wall thickness was $1 \cdot 375$. Laboratory investigations, which included karyotype, urine chromatography for amino acids and sugars, and serum aldolase, lactic acid, and pyruvic acid, were all within normal limits. The serum CK was normal on two separate occasions (18 IU and 12 IU).

Electromyography done on three separate occasions (at the ages of 8,12 , and 20 months) from the deltoid and gluteus maximus muscles was summarised as excluding neurogenic disease and being only very slightly suggestive of a myopathic process. Nerve conduction was normal.

Muscle biopsy was performed with the needle technique from the right quadriceps. The specimen was processed according to the methods described by Dubowitz and Brook (1973). On light microscopy, there were only minor changes in the muscle biopsy. The fibres appeared rounded and small. There were variations in size, occasional splitting of fibres, and some central nuclei. The enzyme histochemistry NADH and myosin ATPase showed the normal mosaic pattern with mild type II atrophy. The average size of type I fibres was $25 \cdot 3 \mu$, and that of the more variable type II fibres $20.6 \mu$ (Fig. 2). On electron microscopy, there were foci of myofibrillar atrophy and accumulation of glycogen, usually in the subsarcolemmal area. In the same areas, vacuolar and membranous structures were found (Fig. 3). Around some blood vessels, there was

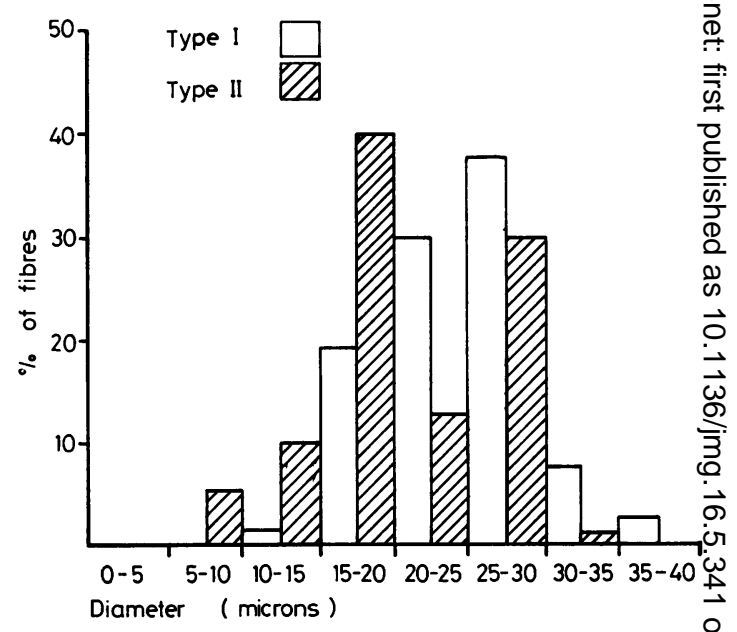

Fig. 2 Percentage distribution of type I and II fibre size.

layering of the basement membrane (Fig. 4). The changes were considered to be mild to moderate and non-specific.

The child collapsed suddenly and unexpectedly at the age of 22 months at home while awake in the presence of the mother. He was dead on arrival hospital. Resuscitation was successful for a period of 14 hours but the patient died finally without gaining consciousness. Necropsy recorded pneumonia as the cause of death. There was cardiac hypertrophy. The heart weight was $70 \mathrm{~g}$ (normal $56 \mathrm{~g}$ ). The thickness of both the interventricular septum and the posterior left ventricular wall was $1 \mathrm{~cm}$. There was some sligh irregularity in heart muscle fibre arrangement, bu not to the marked degree reported by Maron et $\vec{a}$ (1974). Some very small fat droplets were observed in both the heart and skeletal muscle fibres.

\section{Family reports}

SIBSHIP OF PROPOSITUS (IV.9)
The parents were Sephardic Jews born in Turke The father and mother were born in 1935 and 195 , respectively. They were first cousins (Fig. 5). They had normal karyotypes and echocardiograms. The mother had had 7 miscarriages, the pregnancio ending between the second and the sixth months. The oldest sister of the propositus (IV.5), botn 17.3.64, died suddenly and unexpectedly at the age of 16 months. She died at home in the morning after drinking water. Necropsy gave gastric content aspiration as the cause of death.

The second sister (IV.6), born 2.10.65, die suddenly and unexpectedly at the age of 11 years 


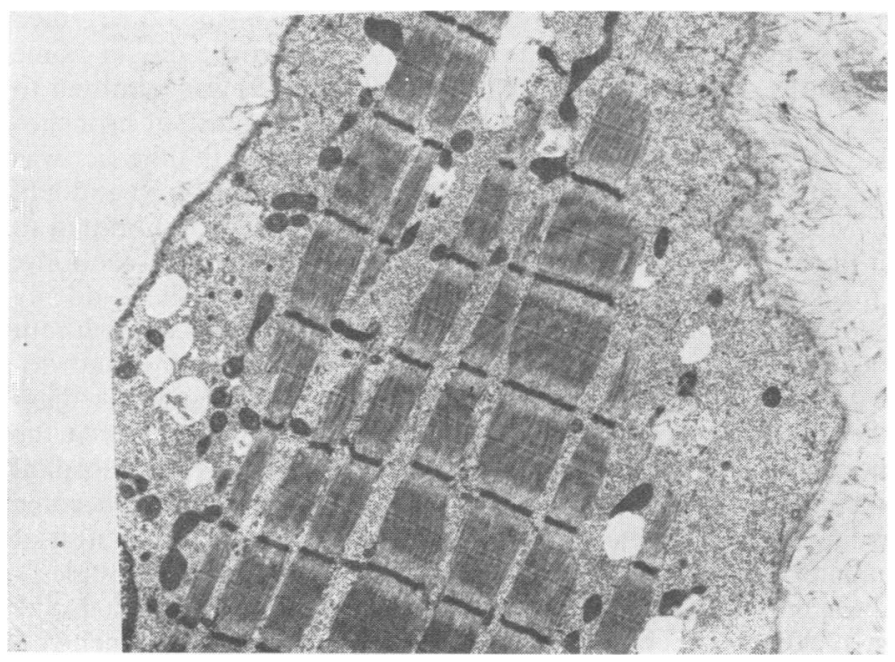

Fig. 3 Electron microscopy, foci of myofibrillar atrophy and accumulation of glycogen granules, vacuolar and membranous structures.

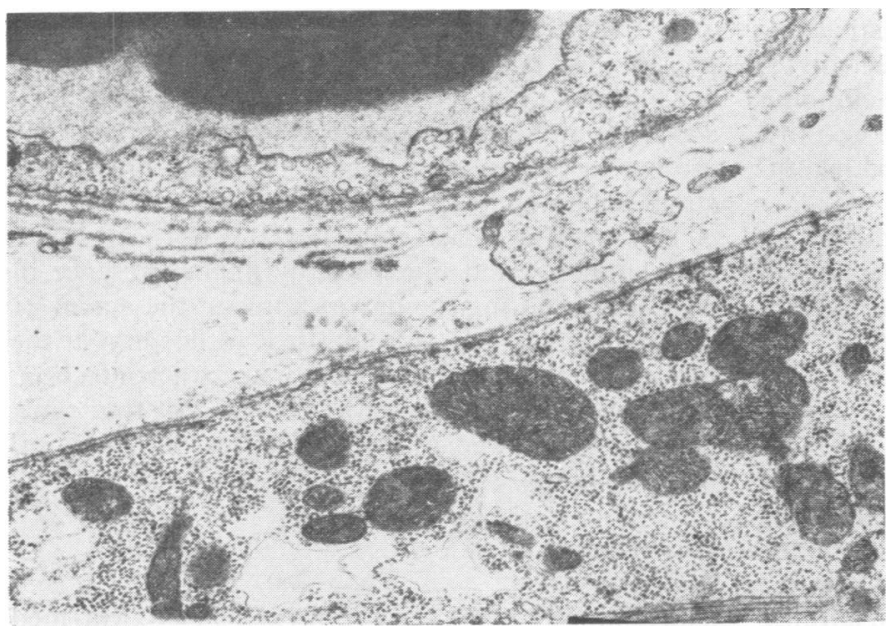

Fig. 4 Electron microscopy, layering of basal membrane around blood vessels.

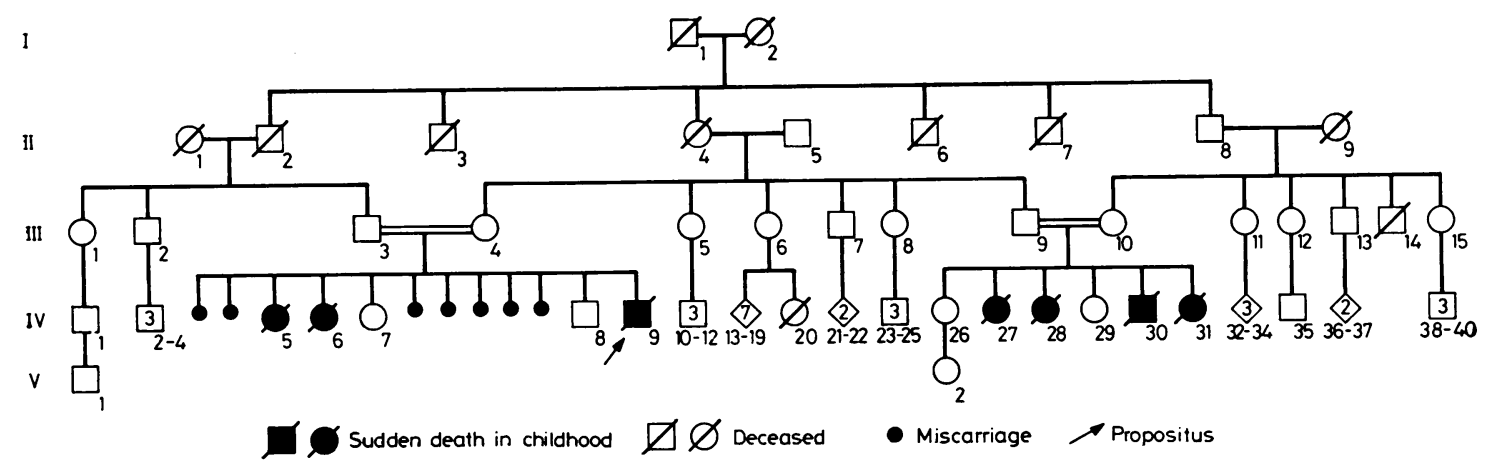

Fig. 5 Family pedigree. 
4 months. The parents noticed that from infancy she made few spontaneous movements, and sitting and standing were delayed. At the age of $6 \frac{1}{2}$ months, a grade $2 / 3$ systolic murmur was recorded; at the age of 2 years, the diagnosis of benign muscular hypotonia was made. At the age of 4 years, a biopsy from the quadriceps muscle was investigated. Muscle striation was preserved in most fibres. Slight fibrosis with slight increase of collagen fibres of the perimesium and endomesium was recorded. The pathological findings were considered to be too meagre to make a diagnosis. At the age of 9 years, the girl was admitted to hospital after falling from bed and losing consciousness for a short time. At the age of 10 years, electromyography showed increased numbers of potentials of short duration in the deltoid and quadriceps muscles that were compatible with a diagnosis of muscular dystrophy. Median nerve conduction was normal. At the age of $10 \frac{1}{2}$ years, the child had difficulty in climbing steps, and neurological examination showed decreased muscle strength of arms and thighs and non-elastic consistency of the calves. CK (13 IU) and electrolytes were normal. The child died suddenly while climbing steps at school. There was no necropsy. The third sister (IV.7) is now 12 years old and in good health. Her echocardiogram was normal.

The brother (IV.8) is now 5 years old and suffers from obesity and Perthes disease; he was operated on because of bilateral congenital stenosis of the ureteropelvic junction. He has no muscle disease. His echocardiogram was within normal limits.

\section{SECOND SIBSHIP}

The parents were first cousins (Fig. 5, 11I.9, 10). The father and mother were born in 1933 and 1939, respectively. The father is a maternal uncle of the propositus and a cousin of his father, while the mother is a cousin of both parents of the first sibship. The echocardiogram of the mother (III.10) was normal, while that of the father (III.9) showed a marked increase in septal thickness $(21 \mathrm{~mm})$ and mild left ventricular hypertrophy. The ratio of interventricular septum to posterior left ventricular wall thickness was $1 \cdot 75$. The oldest daughter (IV.26) is a healthy 20-year-old woman and mother of a healthy child.

The second daughter (IV.27) born 19.10.60, died suddenly and unexpectedly in the arms of her mother after a meal at home at the age of 21 months. She was admitted to hospital at 7 months because of gastroenteritis and at 11 months for vomiting. The necropsy recorded interstitial pneumonia, oedema of the brain and spinal cord, and acute dilation of the right heart chamber. Oedema was found between the heart muscle fibres.
The third daughter (IV.28), born 1.5.63, die suddenly and unexpectedly during the day at home at the age of 22 months. This child was admitted t $\overrightarrow{\overrightarrow{\sigma^{2}}}$ hospital at the age of 3 months because of broncho: pneumonia and vomiting; at that time it was recorded that she did not hold her head up and ha電: generalised hypotonicity. She was again admitted to hospital at the age of 5 months because of vomiting? At 6 months, while eating at home, she suddenly became cyanotic and lost consciousness withou coughing. The child was resuscitated by mouth-tomouth breathing. Aspiration pneumonia was diag్ nosed and hypotonicity was again recorded. At the. age of 16 months, she was again brought to hospita because she had stopped breathing and had becoms cyanotic suddenly while she was in good health ait home. The episode was thought to be a breath holding attack. Electrocardiogram was normal. She left hospital after 12 days and died suddenly $\&$ months later. Necropsy gave aspiration of gastrie content as the cause of death.

The fourth daughter (IV.29) is now 12 years ol $\$$ and in good health.

The fifth child (IV.30), a son born 11.5.68, died. suddenly and unexpectedly while walking with his mother in the street at the age of 22 months. Interstitial pneumonia was recorded at necropsy.

The sixth and last child (IV.31), born 19.11.70 died suddenly and unexpectedly in the presence of her mother during the day at home at the age of 2 क months. This infant was admitted to hospital at the age of 8 months because of urinary tract infection and no other pathology was recorded at that time Necropsy showed myocarditis on histologicat investigation.

\section{Discussion}

The finding of 7 children ( 2 boys and 5 girls) who die suddenly and unexpectedly in two related sibships? the offspring of 2 consanguineous marriages, suggests an autosomal recessive disease. In each sibship, there were also healthy children. The facs that the propositus had a cardiomyopathy detecte by echocardiography suggested that the underlyin $\overline{\overline{\mathbf{B}}}$. cause of death in the related children was an unde? tected cardiomyopathy accompanying a mild anty often subclinical generalised myopathy. This hypow thesis gains support by the diagnosis of myopathy in the sister (IV.6), who died at the age of 11 years Furthermore, the parents brought the propositus to the paediatrician (EV) stating that he was an inactive baby, as was the daughter (IV.6), and that they wero afraid that he might have the same condition. The $\overline{6}$ children (IV.5, 9, 27, 28, 30, and 31) died in the second year of life, a rare occurrence in sudden infant 
death, which usually occurs in the first year of life (McWeeny and Emery, 1975). Another unusual feature of the sudden death in this family is that it never occurred during sleep (Valdes-Dapena, 1967). Sudden infant death syndrome appears to be less common in Israel than in other countries (Bloch, 1973; Winter and Emetarom, 1973). Sudden infant death is probably a syndrome of many aetiologies and, while affected sibs are known, the proportion in pooled data is much lower than would be expected from Mendelian segregation (Marx, 1975). The high proportion of affected sibs in the present family, above the expected rate in a recessive disease, is probably because of the biased ascertainment. As miscarriages occurred only in one of the two affected sibships, the cause of them, though unknown, is probably unrelated to the sudden deaths. However, an increased frequency of spontaneous abortions in mothers who conceived after a child had died of sudden infant death syndrome has been reported (Mandell and Wolfe, 1975).

The rare cases of sudden unexpected death in the second year of life should, in the future, be analysed separately from the much more common ones occurring in the first year. By doing so, it may perhaps be possible to obtain an estimate of the frequency of this or other autosomal recessive genes which may cause sudden death between the ages of one and two years. The search for different causes of sudden infant death and associated factors, such as social class and sleep apnoea, is proceeding and scoring systems for identifying infants at risk have been used (Carpenter et al., 1977).

Fraser (1976) has mentioned the association of the cardioauditory syndrome and related cardiac conditions with 'crib death'. In the present family none of the children was deaf, the electrocardiogram of those tested was normal, and most of them did not have episodes of loss of consciousness. We conclude that the children in this family did not have the cardioauditory syndrome. The more common forms of cardiac arrythmias usually disappear a few months after birth (Southall et al., 1977). Clark et al. (1973) and Epstein (1974) have suggested that idiopathic hypertrophic subaortic stenosis or asymmetric septal hypertrophy are caused by a dominant gene with incomplete penetrance, with most cases being undiagnosed. The 7 children who died suddenly in this family may have been homozygous for the gene that causes asymmetric septal hypertrophy in the heterozygote. Though all four obligatory heterozygotes (III.3, 4, 9, and 10) were examined clinically and by echocardiogram, only findings in III.9 were compatible with asymmetric septal hypertrophy. As the nosological entity of idiopathic hypertrophic subaortic stenosis is still not well defined (Bulkley,
1977), the question of the relation between this family and the above entity remains open. It is well known that asymmetric septal hypertrophy may cause sudden death (Paré et al., 1961; Braunwald et al., 1964), but this has been documented in adults and in children over the age of two years and infants who died from the disease did not die suddenly (Maron et al., 1974).

While in some cases obvious changes are detected in the heart at necropsy, in others they are undetectable (Robinson, 1976). Congenital muscular dystrophy, first named by Howard (1908), may be a heterogeneous entity (Donner et al., 1975). The propositus walking unaided at 20 months, never having any contractures, though showing some pathology on muscle biopsy and less on electromyography, and having completely normal serum enzymes is not the typical picture of the usual congenital muscular dystrophy, or the various congenital myopathies (Dubowitz and Brooke, 1973). The possibility is entertained that the gene described in this family may manifest on echocardiogram in some heterozygotes as asymmetric septal hypertrophy, while in the homozygous state causing both a mild generalised myopathy, and a more severe cardiomyopathy with sudden unexpected death usually in the second year of life.

\section{References}

Bloch, A. (1973). Sudden infant death syndrome in the Ashkelon district: a 10-year survey. Israel Journal of Medical Sciences, 9, 452-458.

Braunwald, E., Lambrew, C. T., Rockoff, S. D., Ross, J. Jr., and Morrow, A. G. (1964). Idiopathic hypertrophic subaortic stenosis. I. A description of the disease based upon an analysis of 64 patients. Circulation, Suppl. 4, 3-119.

Bulkley, B. H. (1977). Idiopathic hypertrophic subaortic stenosis afflicted idols of the cave and the marketplace. American Journal of Cardiology, 40, 476-479.

Carpenter, R. G., Gardner, A., McWeeny, P. M., and Emery, J. L. (1977). Multistage scoring system for identifying infants at risk of unexpected death. Archives of Disease in Childhood, 52, 606-612.

Clark, C. E., Henry, W. L., and Epstein, S. (1973). Familial prevalence and genetic transmission of idiopathic hypertrophic subaortic stenosis. New England Journal of Medicine, 289, 709-714.

Donner, M., Rapola, J., and Somer, H. (1975). Congenital muscular dystrophy: a clinico-pathological and follow-up study of 15 patients. Neuropädiatrie, 6, 239-258.

Downham, M. A. P. S. (1977). Working party for early childhood deaths in Newcastle. Newcastle survey of deaths in early childhood $1974 / 1976$ with special reference to sudden unexpected deaths. Archives of Disease in Childhood, $52,828-835$.

Dubowitz, V., and Brooke, M. H. (1973). Muscle Biopsy: A Modern Approach. Major Problems in Neurology, Vol. 2. Saunders, London.

Epstein, S. E. (1974). Asymmetric septal hypertrophy. Annals of Internal Medicine, 81, 650-680.

Fraser, G. R. (1976). The Causes of Profound Deafness in Childhood, p. 43. Baillière Tindall, London. 
Howard, R. (1908). A case of congenital defect of the muscular system (dystrophia muscularis congenita) and its association with congenital talipes equinovarus. Proceedings of the Royal Society of Medicine, 1, 157-166.

McWeeny, P. M., and Emery, J. L. (1975). Unexpected postneonatal deaths (cot deaths) due to recognisable disease. Archives of Disease in Childhood, 50, 191-196.

Mandell, F., and Wolfe, L. C. (1975). Sudden infant death syndrome and subsequent pregnancy. Pediatrics, 56, 744-776.

Maron, B. J., Edwards, J. E., Henry, W. L., Clark, C. E., Bingle, G. J., and Epstein, S. R. (1974). Asymmetric septal hypertrophy (ASH) in infancy. Circulation, 50, 809-820.

Marx, J. L. (1975). Crib death: some promising leads but no solution yet. Science, 189, 367-369.

Paré, J. A. P., Fraser, R. G. Pirozynski, W. J., Shanks, J. A., and Stubington, D. (1961). Hereditary cardiovascular dysplasia: a form of familial cardiomyopathy. American Journal of Medicine, 31, 37-62.

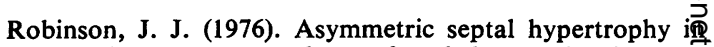
autopsies on men. Archives of Pathology and Laboratorix Medicine, 100, 121-122.

Southall, D. P., Orrell, M. J., Talbot, J. F., Brinton, R. J? Vulliamy, D. F., Johnson, A. M., Keeton, B. R., Andersoof R. M., and Shinebourne, E. A. (1977). Study of cardia arrythmias and other forms of conduction abnormality ifp newborn infants. British Medical Journal, 2, 597-599.

Valdes-Dapena, M. A. (1967). Sudden and unexpected deat in infancy: a review of the world literature 1954-1960 Pediatrics, 39, 123-138.

Winter, S. T., and Emetarom, N. B. (1973). Sudden infan $\vec{\oplus}$ death: a pilot enquiry on its frequency in Israel. Israet Journal of Medical Sciences, 9, 447-451.

Requests for reprints to Dr K. Fried, Departmen of Genetics, Asaf Harofe Hospital, Zerifin 70300 Israel. 